\title{
El rol de los jueces en el marco de la 'lucha contra el delito' en el Sur Global: un análisis comparativo de los casos de la Provincia de Buenos Aires y Metro Manila
}

\author{
The Role of Judges in the 'War Against Crime' in the Global South: \\ A Comparative Analysis of the Cases of the Province of Buenos \\ Aires and Metro Manila \\ O papel dos juízes no marco da 'luta contra o delito' no Sul Global: \\ uma análise comparativa dos casos da Província de Buenos Aires e \\ Grande Manila
}

\section{PABlO CIOCCHINI}

FECHA DE RECEPCIÓN: 10 DE ENERO DE 2019. FECHA DE APROBACIÓN: 7 DE MAYO DE 2019

Doi: http://dx.doi.org/10.12804/revistas.urosario.edu.co/sociojuridicos/a.7910

Para citar este artículo: Cioccini, P. (2019). El rol de los jueces en el marco de la 'lucha contra el delito' en el Sur Global: un análisis comparativo de los casos de la Provincia de Buenos Aires y Metro Manila. Estudios Socio-Jurídicos, 21(2), 73-104. Doi: http://dx.doi.org/10.12804/revistas.urosario.edu.co/sociojuridicos/a.7910

\section{RESUMEN}

En las últimas décadas se ha presenciado globalmente el surgimiento de un populismo penal de la mano del miedo al delito. Este fenómeno ha adquirido características especiales en los países del Sur Global, en dónde la sensación de inseguridad se ha agravado por la ineficacia de las agencias estatales encargadas de lidiar con el delito. La corrupción y el abuso policial vuelven el populismo penal en el Sur Global aún más peligroso que en los países del Norte Global. En este contexto, el rol de control de legalidad sobre el accionar policial que ejerce en forma indirecta la justicia penal, y en especial de los jueces, es muy importante; sin embargo, la ineficacia de la justicia penal limita su intervención. Aún más, reformas que buscaron mejorar su eficacia han limitado su capacidad de controlar los procedimientos policiales. En este artículo se compara el rol que cumplen los jueces en

* Profesor de la Universidad de Liverpool donde enseña Criminología Crítica y Sociología Jurídica. Es abogado por la Universidad Nacional de La Plata (Argentina), Magister en Sociología Jurídica por el Instituto Internacional de Sociología Jurídica de Oñati (País Vasco) y Doctor en Sociología Jurídica por la Universidad del País Vasco. Correo electrónico: p.cioccnini@liverpool. ac.uk 
casos penales en la Provincia de Buenos Aires (Argentina) y Metro Manila (Filipinas). El análisis comparativo demuestra que, en ambos casos, la situación es preocupante. Los jueces han perdido el liderazgo en las políticas de castigo del delito y su rol de contralor de la legalidad de las prácticas policiales está seriamente debilitado.

Palabras clave: justicia penal, reforma penal, jueces, control de legalidad, Argentina, Filipinas.

\section{ABSTRACT}

In recent decades, we have witnessed the global emergence of penal populism as a response to the rising fear of crime. This phenomenon has acquired special characteristics in the countries of the Global South where the inefficiency of the state agencies in charge of dealing with crime aggravates the perception of insecurity. Corruption and police abuse make penal populism in the Global South even more dangerous than in the countries of the Global North. In this context, the indirect control exerted by courts over the legality of police behavior is crucial. However, the inefficiency of courts has limited the range and effectiveness of their interventions. Furthermore, an unintended consequence of legal reforms that sought to improve courts' effectiveness is that they have restrained courts' capacity to control police procedures. This article compares the role judges plays in criminal cases in the Province of Buenos Aires (Argentina) and Metro Manila (Philippines) regarding police behavior. The comparative analysis shows that, in both cases, the situation is worrisome. The judges have lost the moral leadership on criminal justice matters, and their role controlling the legality of the police behavior has weakened extremely.

Keywords: Criminal justice, courts' reform, judges, control of legality, Argentina, Filipinas.

\section{RESUMO}

Nas últimas décadas se tem testemunhado globalmente o surgimento de um populismo penal da mão do medo ao delito. Este fenômeno tem adquirido características especiais nos países do Sul Global onde a sensação de insegurança se tem agravado pela ineficácia das agências estatais encarregadas de lidar com o delito. A corrupção e abuso policial tornam o populismo penal no Sul Global ainda mais perigoso que nos países do Norte Global. Neste contexto o papel de controle de legalidade sobre o acionar policial que exerce em forma indireta a justiça penal, e em especial dos juízes. é muito importante. No entanto, a ineficácia da justiça penal limita sua intervenção. Para além, reformas que buscaram melhorar sua eficácia têm limitado sua capacidade de controlar os procedimentos policiais. Neste artigo se compara o papel que cumprem os juízes em casos penais na Província de Buenos Aires (Argentina) e Grande Manila. A análise comparativa demostra que, em ambos os casos, a situação é preocupante. Os juízes têm perdido a liderança nas políticas de castigo do delito e seu papel de controlador da legalidade das práticas policiais está seriamente debilitado.

Palavras-chave: justiça penal, reforma penal, juízes, controle de legalidade, Argentina, Filipinas 


\section{Introducción}

La sensación de inseguridad y la preocupación por el delito son fenómenos globales que han moldeado la agenda política y han puesto en cuestión a los sistemas penales, tanto en los países del Norte como en los del Sur Global. Sin embargo, el desafío para los sistemas penales del Sur Global ha sido doble, ya que este fenómeno se ha dado al mismo tiempo que las instituciones del sistema penal eran sujetas a procesos de reformas con el fin de democratizar sus prácticas y superar de esta forma el legado de los previos regímenes autoritarios y semi-autoritarios. De esta forma, mientras que, por un lado, un grupo de políticos y de medios de comunicación respaldaban el reclamo de un importante sector de la

población por otorgar mayores atribuciones a la policía y castigos más severos para los criminales, por el otro, sectores del gobierno, junto con diversos grupos relacionados con la protección de los derechos humanos, y el respaldo de organismos financieros internacionales, promovían reformas cuyo objetivo era mejorar la transparencia del sistema y el control de la legalidad de las fuerzas policiales. Es en este contexto en el que se debe analizar el rol de los jueces. Mientras que la función principal de los jueces es la de proveer justicia a través de sus sentencias, ya sea castigando o absolviendo a quienes han sido acusados de cometer delitos, una función relacionada con esta es la de controlar la legalidad de la investigación policial, protegiendo a la sociedad del abuso del poder estatal.

Los estudios criminológicos críticos han focalizado su análisis en las causas del delito y, en su caso, el rol de la policía, sin prestar el mismo nivel de atención al rol que cumple la institución judicial. Por otra parte, los estudios de sociología jurídica, más escasos que los primeros, han tendido a analizar el funcionamiento interno de la institución judicial sin profundizar suficientemente en el contexto en el que operan (Flom $\mathcal{E}$ Post, 2016). Este trabajo incorpora elementos de las dos tradiciones para analizar el rol que cumplen los jueces encargados de los casos penales en Argentina y Filipinas. Se sostiene que en ambos casos los jueces han perdido liderazgo en las políticas de prevención y castigo del delito, y como consecuencia se ha debilitado su rol de contralor de la legalidad de las prácticas policiales. En el caso de Argentina, los jueces han sido objeto de críticas desde el sector político y los medios de comunicación. 
Junto a estas críticas, sucesivas reformas procesales les han quitado a los jueces protagonismo en favor de los fiscales en el proceso penal. Los jueces ocupaban un rol fundamental al interpelar al poder policial y político a través de su actuación en el proceso que los fiscales no han de reemplazar. En el caso de Filipinas, los jueces han sido relegados a un lugar secundario en las políticas criminales, mientras que el poder ejecutivo respalda la violencia policial. Las sucesivas reformas judiciales que han buscado mejorar la eficacia, eficiencia y transparencia del poder judicial poco han ayudado a fortalecer la posición de los jueces en el contexto de violencia estatal y delictual en el que deben operar. Esta situación se ha visto agravada por la masiva entrada de casos fruto de la "guerra contra las drogas" declarada por el presidente de Filipinas, Rodrigo Duterte. En ambos casos se evidencia la necesidad de fortalecer el rol de los jueces en el proceso penal para de esta forma limitar los excesos del poder policial.

El artículo está organizado en tres secciones. La primera sección explica la elección de Argentina y Filipinas como casos de estudio y describe la metodología usada en el análisis. Las secciones segunda y tercera analizan los casos de Argentina y Filipinas, respectivamente. Por último, se ofrecen una serie de reflexiones sobre el potencial explicativo de los análisis comparativos críticos entre jurisdicciones del Sur Global y las necesidades específicas de estas sociedades.

\section{Metodología: casos comparados}

A pesar de las diferencias entre los países del Sur Global sus juzgados y tribunales enfrentan desafíos comunes, que se pueden identificar a través de un enfoque comparativo. Este trabajo compara la situación de los jueces penales tras las reformas a los tribunales penales de Argentina, centrándose en la Provincia de Buenos Aires (PBA) y las implementadas en Filipinas, centrándose en Metro Manila. Estas reformas han sido cualitativamente distintas, pero en ambos casos tuvieron como uno de sus objetivos centrales eliminar la demora judicial. Para esto, en ambos casos, se simplificaron procedimientos y favorecieron el uso de mecanismos alternativos al juicio oral para resolver los casos. En particular, se ha favorecido el uso del juicio abreviado o plea barganining en ambas 
jurisdicciones. La comparación de dos sociedades semiperiféricas del Sur Global evita la trampa de presentar a uno de los sistemas como un "modelo" o "estándar" contra el cual medir el otro y ayuda a desarrollar un enfoque más reflexivo. Tanto Argentina como Filipinas han sufrido regímenes autoritarios. En el caso de Argentina ha sufrido numerosos golpes de estado durante el siglo 20. La última dictadura militar, responsable por la desaparición de 30.000 personas, gobernó entre los años 1976 y 1983 (CONADEP, 2010). En el caso de Filipinas, Ferdinand Marcos gobernó desde 1965 a 1986. Desde 1972 hasta 1981 se impuso la ley marcial. El gobierno de Marcos es responsable de más de miles de ejecuciones extrajudiciales y cientos de desaparecidos (Chua). En ambos casos, estos gobiernos autoritarios fueron sucedidos por gobiernos democráticos. También en ambos casos, la policía es acusada de corrupción y brutalidad, parcialmente legado de dicho pasado autoritario (Ugolini, 2017; HRW, 2011).

Argentina es un país federal compuesto por 23 provincias y una ciudad autónoma, todas las cuales tienen sus propios sistemas judiciales. Sin embargo, estos sistemas son muy similares, comparten contextos socioeconómicos comunes y una sólida tradición legal. La PBA fue elegida para este estudio porque es la provincia más grande y poblada de Argentina, hogar de más de 15 millones de habitantes que representan aproximadamente al $40 \%$ de la población del país. La mayoría de la población de la PBA vive en el conurbano bonaerense, el área urbana que rodea a la ciudad de Buenos Aires (que es autónoma y tiene su propio sistema judicial). El área tiene un alto grado de industrialización, pero también gran conflictividad social debido a las marcadas desigualdades sociales, el crecimiento demográfico junto con el déficit de calidad y la falta de disponibilidad de los servicios urbanos y domiciliarios (Suárez E Palma Arce, 2010, p. 25); además, sufre una de las mayores tasas de criminalidad en Argentina (Ministerio de Seguridad de la Nación, 2017). En 1996, la PBA se convirtió en una de las primeras jurisdicciones de América Latina en adoptar un sistema adversarial y también fue una de las primeras en adoptar reformas inspiradas en la gestión a mediados de la década de 2000.

Por su parte, Metro Manila es la región metropolitana de Manila, la capital de Filipinas. Es un área altamente industrializada y urbanizada 
con más de 12 millones de habitantes. La ciudad está caracterizada por una alta desigualdad social y económica, los asentamientos ilegales y deficientes servicios urbanos (Ragragio, 2003). Filipinas adoptó el sistema adversarial hace más de un siglo, durante el tiempo que sufrió gobierno colonial de los Estados Unidos. Sin embargo, al igual que en Argentina, en Filipinas se han implementado una serie de reformas judiciales con el objetivo de modernizar y mejorar la eficiencia sus tribunales y la legislación sobre procedimientos penales.

El análisis comparativo de los marcos legales y procedimientos penales que estructuran a los tribunales no es suficiente para comprender las políticas de la institución judicial y de la racionalidad que gobierna las interacciones cotidianas de los actores judiciales. Dicho análisis jurídico debe ser completado con un análisis cualitativo de las prácticas judiciales. Este análisis socio-legal se basa en múltiples fuentes de datos que incluyen la legislación relevante, los informes publicados por el gobierno, las declaraciones públicas sobre estos asuntos por funcionarios del gobierno, entrevistas con informantes claves (actores judiciales locales) y la observación de audiencias en los tribunales. De esta forma, el análisis busca comprender los diferentes intereses en juego en el sistema judicial penal, prestando particular atención a la situación de los jueces y sus relaciones con la policía, los fiscales y el gobierno.

Este artículo continua la línea de investigación establecida por los estudios de sociología jurídica penal, que centran su análisis en las dimensiones más problemáticas de la justicia penal: su lentitud y las reformas implementadas para acelerar su funcionamiento, los usos de la prisión preventiva y los discursos que los justifican, la tensiones entre los procedimientos orales y la permanencia del expediente judicial, el uso del juicio abreviado y la suspensión del juicio a prueba, y la relación de la justica con la prensa (Ciocchini \& Kostenwein, 2017; Ganon, 2008; Bergman \& Langer, 2015; Palmieri et al. 2004; Hazán \& Riego, 2007; Hazán \& Iud, 2010). Estos estudios ofrecen un análisis detallado del impacto de las reformas judiciales. Palmieri et al. (2004) describen los serios problemas que sufría la justicia penal en la PBA años después de implementar el sistema acusatorio. Ganon (2008), en tono crítico, sostiene que el énfasis de la segunda ola de reformas realizadas en la PBA, con su foco en la eficacia y eficiencia, resultan en la 'macdonalización' 
de la justicia penal. Hazán y Riego (2007) y Hazán y lud (2010) ofrecen una perspectiva más optimista, reconociendo las limitaciones de dichas reformas y algunos de sus aspectos más problemáticos, pero concluyendo que, en términos generales, la reducción de los tiempos del proceso penal favorece a los acusados. Por su parte, Kostenwein (2016) sostiene que las reformas han tenido un cambio significativo en las prácticas judiciales, pero no necesariamente en el uso de la prisión preventiva, principal mecanismo de control social. Esta continuidad, o según Ganon (2008) expansión, del punitivismo, es explicada por Gutiérrez (2014) como resultado de la fuerza del discurso antiimpunidad que crece durante las primeras décadas de democracia y logra fundirse con el discurso por la seguridad contra el delito, es decir "la impunidad es inseguridad, y la inseguridad es un problema" (p. 79). Ciocchini (2013b, 2014, 2018) ofrece otro aspecto del crecimiento del punitivismo al analizar tanto el rol legitimador de las reformas que ha tenido el discurso de la 'demora judicial', como el gerencialismo con el que han permeado la racionalidad de los actores judiciales. Este gerencialismo impregna las prácticas diarias del sistema judicial que son evaluadas formal e informalmente cada vez en mayor medida en relación a su productividad y no a la calidad de sus fundamentos. Pero incluso esta productividad es cuestionada por Bergman y Langer (2015). Los autores comparan los plazos de los procesos de la PBA y de la Ciudad Autónoma de Buenos Aires, en dónde rige un sistema hibrido, y sostienen que el impacto de las reformas no ha sido tan significativo.

Este artículo retoma estas discusiones, centrándose en la perdida de 'liderazgo' de los jueces en ambas jurisdicciones. El concepto de liderazgo utilizado en este estudio pretende captar el impacto directo e indirecto que tienen los jueces penales en las políticas criminales. Si bien los jueces han perdido la dirección de la policía en la investigación penal con el cambio al sistema acusatorio, todavía tienen la capacidad de impactar en forma indirecta en la labor policial. Al interpretar la ley penal en su labor diaria definen frente a los otros actores de la justicia penal (fiscales, defensores, policía, etc.) el alcance y aplicación de la misma. Por otra parte, al evaluar testimonios, pericias y otros tipos de evidencia, definen los criterios de investigación policial y/o fiscal. A su vez, sus sentencias, tanto las condenatorias como las absolutorias, comunican a la comunidad 
el sentido de justicia. Es en este sentido es que sostenemos que los jueces ejercen un liderazgo moral y político. Sin embargo, se observa cómo la crisis del sistema judicial junto con el grave incremento de sensación de inseguridad ha afectado gravemente su legitimidad y, en consecuencia, han perdido dicho liderazgo. Más aún, los cambios llamados a acelerar la resolución de causas los han restringido a un rol menos activo, en el cual ejercen un control técnico indirecto, y en la mayoría de los casos se limitan a convalidar las decisiones tomadas por fiscales o la policía.

Este artículo contrasta los resultados del trabajo de campo realizado en el PBA en los años 2010 y 2014 con los de la investigación realizada en Filipinas entre 2017 y 2018. El trabajo de campo en el PBA consistió en entrevistas semiestructuradas con jueces, fiscales y abogados públicos. De las 51 entrevistas realizadas, 45 lo fueron en 2010 y 6 en 2014. A su vez, durante 2010 se observó el funcionamiento de tres juzgados penales. La investigación en Filipinas consistió en 50 entrevistas con fiscales y jueces en la ciudad de Manila realizadas entre 2017 y 2018 y la observación de los procedimientos judiciales en un juzgado regional de primera instancia. Las entrevistas y observaciones se complementaron con el análisis de la legislación procesal penal, las propuestas de reforma organizacional de los juzgados, los informes elaborados por el gobierno y por los grupos que propulsan reformas, y los informes periodísticos que dan cuenta de la actuación de los juzgados en la "guerra contra las drogas".

\section{Argentina: del modelo adversarial al gerencialismo}

En la PBA los jueces penales han perdido liderazgo en las políticas criminales a causa de la combinación de dos factores: su poca legitimidad frente a la población y un rol muy reducido en los procedimientos penales reformados. Por un lado, los jueces han perdido legitimidad por el constante ataque discursivo por parte del gobierno y los medios de comunicación, acusándolos de no castigar a los criminales e impedir que la policía actué eficazmente. Por el otro, su rol ha sido reducido a través de las sucesivas reformas procesales penales que se han llevado a cabo. Estas reformas tuvieron como objetivo inicial el garantizar el debido proceso, pero luego pasaron a priorizar la eficiencia de los tribunales incluso por 
sobre las garantías de los acusados; en pos de alcanzar esta eficiencia, las reformas han incentivado a los actores judiciales a negociar la culpabilidad en lugar de llevar la causa a juicio.

\section{Las reformas procesales}

La PBA es un ejemplo paradigmático de las transformaciones que han sufrido los procedimientos penales en América Latina. El antecedente más importante a las reformas de la PBA en Argentina fue el intento de reforma del Código de Procedimientos Penales (CPC) de la jurisdicción federal en la década de los ochenta. Este último fue el primero de los proyectos de reforma procesal en América Latina en el marco de la transición hacia la democracia. En la región, a comienzos de los años ochenta regían códigos de procedimiento penal centenarios. A partir del proyecto de CPC en Argentina se formó una red de académicos latinoamericanos que promovió el reemplazo de los códigos vigentes, a los que calificaron como "inquisitoriales", por códigos basados en el sistema adversarial (Langer, 2007). El rasgo común de estas reformas fue el objetivo de implementar sistemas adversariales en la justicia penal. Se ha denominado a estas reformas, fruto del liderazgo mundial estadounidense, la "revolución del debido proceso" (Vogler, 2005). Estas reformas contaron con el apoyo financiero de organizaciones financieras internacionales como el Banco Mundial y el Banco Interamericano de Desarrollo, y de agencias de cooperación como USAID, la Sociedad Alemana para la Cooperación Técnica, la Fundación Konrad Adenauer y el Programa de las Naciones Unidas para el Desarrollo, entre otros. En 1992, la provincia de Córdoba, en Argentina, y Guatemala fueron las primeras jurisdicciones en la región en adoptar CPC basados en el sistema adversarial. Dos décadas después, más de 14 países latinoamericanos habían reformado sus CPC.

La principal preocupación en la primera ola de reformas procesales fue la sustitución de los procedimientos formales y escritos por otros menos formales, en los cuales las decisiones judiciales más relevantes, en especial la sentencia, fueran decididas en el marco de una audiencia oral y pública. Había consenso entre los reformadores en cuanto a que los procedimientos escritos habían generado burocratizado a la administración de justicia y eran la causa de la crónica demora que experimentaban los tribunales 
(Duce, 2009). La demora judicial, en conjunto con el uso generalizado de la prisión preventiva, era una de las causas de la superpoblación carcelaria. Más de la mitad de la población carcelaria en América Latina consistía en acusados sin condena firme, es decir, no habían sido juzgados o habiéndolo sido no se había resuelto su apelación (Carranza, 1996).

La red de académicos que promovían las reformas procesales sostenía que los sistemas adversariales eran más transparentes y eficientes (Ciocchini, 2013b). Afirmaban que el juicio oral y público brindaría transparencia y permitiría tomar las decisiones judiciales necesarias para erradicar las prácticas autoritarias. También aseguraban que la eliminación del expediente judicial aliviaría notablemente la carga de trabajo. Por su parte, se sostenía que el juicio oral evitaría la postergación en el tiempo de la intervención en la causa de los diversos actores judiciales. De esta forma, fiscales, jueces y abogados defensores se encontraban forzados a tomar decisiones y pronunciarse en forma inmediata durante las audiencias de juicio (Ciocchini, 2013a).

La reforma del CPC de la PBA en 1996 fue un ejemplo paradigmático de este tipo de reformas. En los fundamentos del nuevo CPC se establecía que:

[...] las dificultades que manifiesta la estructura actual [...] se materializan [...] en el congestionamiento de causas, la lentitud del trámite en los procesos, y la consecuente dilación en el dictado de las sentencias [...] generando en la población bonaerense una desalentadora sensación de inseguridad e injusticia, instalando en la opinión pública la idea de que la demora en el juzgamiento se traduce en impunidad. La superpoblación en las cárceles de la Provincia es una de tales consecuencias disvaliosas. (Fundamentos Ley 11.922)

Sin embargo, tal como ocurría en las jurisdicciones con tradición en el sistema adversarial, cómo es el caso de los Estados Unidos o Inglaterra, la reforma del CPC de la PBA (y en forma similar las del resto de América Latina) introdujo mecanismos para evitar el juicio a través de una negociación entre las partes. ${ }^{1}$ La introducción de estos mecanismos contradecía 
los objetivos de la reforma. Por un lado, reconocían que no era posible para el sistema tratar todos los casos a través de juicios orales; por lo tanto, el juicio oral no podía reducir la demora. Por otro lado, no ofrecían la transparencia prometida y que se consideraba necesaria para democratizar la justicia. De hecho, estos mecanismos producían una preocupante concentración de poder en los fiscales al otorgarles poder discrecional para ofrecer o consentir una solución alternativa al juicio. Estos poderes discrecionales se sumaban a las amplias facultades otorgadas a los fiscales en el sistema adversarial del CPC de la PBA: la conducción de la investigación penal (antes a cargo de los jueces de instrucción), la decisión de archivar la causa o acusar al imputado y, finalmente, llevar adelante la acusación durante el juicio.

A comienzos del siglo XXI, luego de dos décadas de reformas, los resultados obtenidos tanto en la PBA como en las otras jurisdicciones de América Latina en las que se habían llevado a cabo reformas no eran los deseados (Palmieri et al., 2004). El Centro de Estudios Judiciales de América (CEJA), una organización internacional con sede en Chile, perteneciente a la Organización de Estados Americanos, encargó una serie de estudios sobre el estado de las reformas procesales. Los estudios mostraban que las audiencias orales eran sistemáticamente evitadas por los actores judiciales que favorecían el uso del expediente judicial y las presentaciones escritas. La demora judicial no se había reducido significativamente. Los fiscales habían delegado la investigación en la policía, tal como lo hacían los jueces de instrucción en el pasado, sin ejercer el control más inmediato que los reformadores prometían (CEJA, 2005a, 2005b, 2008; Duce, 2005; Riego, 2007).

El fracaso de estas reformas en la reducción de la demora judicial y la falta de control sobre la policía se hizo más patente por el incremento del delito y de la sensación de inseguridad que cubrió toda la región desde finales del siglo XX (Bergman, 2006). El delito marcó la agenda política de los gobiernos latinoamericanos y debilitó aún más la limitada legitimidad de la policía y de la administración de justicia penal (Flom \& Post, 2016). Frente a estos fracasos, y la crisis de legitimidad que sufría la institución judicial, comenzó una segunda ola de reformas procesales promovidas por el CEJA. Estas reformas se enfocaron explícitamente en implementar mecanismos para reducir la carga de trabajo de los tribunales y de esta 
forma erradicar la demora judicial. Reconociendo el fracaso de la primera ola de reformas que se habían centrado en el cambio legal, las reformas promovidas por el CEJA se centraron en el cambio organizacional, a través de la promoción de nuevas prácticas judiciales (Binder, 2002; Duce et al., 2002; REDEX, 2010).

En la PBA las reformas se focalizaron en procesar a través de audiencias tempranas los casos en los que el imputado había sido detenido en flagrancia, esto es, mientras cometía el delito o inmediatamente después de haberlo cometido. El CEJA identificó que estos casos ocupaban una parte importante de la carga de trabajo de los tribunales (Hazán \& Riego, 2007). Sin embargo, estos casos, por su propia condición de detenidos en flagrancia, requerían un debate muy limitado sobre los hechos y la autoría, sin medidas probatorias complejas. Las reformas promovidas por el CEJA proponían que en estos casos se buscará negociar una solución alternativa entre las partes al poco tiempo de la detención en una audiencia oral, y que en los casos en que no se llegará a un acuerdo, se realizará sin demoras el juicio oral. El CEJA promovió la creación de oficinas dentro del sistema judicial que coordinaran a las agendas de los diversos actores judiciales y aseguraran la realización de las audiencias orales tempranas. Estas oficinas se denominaron Oficina de Gestión de Audiencias (OGA) en la PBA. Los reformadores sostenían que, al procesar rápidamente los casos en flagrancia, se liberarían recursos que se podrían dedicar a investigar y juzgar los casos más complejos (Hazán E Riego, 2007).

Estas reformas debieron enfrentar múltiples obstáculos. Jueces y fiscales se resistieron a cambiar sus prácticas y, en particular, a ceder sus agendas a las oficinas encargadas de organizar las audiencias (Hazán $\mathcal{E}$ Riego, 2007; Langer, 2007; Ciocchini, 2014, 2018). Si bien el gobierno de la PBA apoyó las reformas, este fue siempre inestable, afectado por las tensiones políticas y la escasez presupuestaria. El problema presupuestario fue particularmente grave, evidente en la falta de personal o de recursos materiales básicos, tales como computadoras o espacio para realizar las audiencias en los tribunales. A pesar de estos obstáculos, las reformas lograron imponer la realización de audiencias tempranas y reducir en forma significativa la duración de los procesos penales en los que el acusado fue atrapado en flagrancia (Pasará, 2015). 
Sin embargo, este éxito en la reducción de la duración de las causas sencillas tuvo también consecuencias negativas. En primer lugar, las reformas agravaron la falta de control por fiscales y jueces de las actuaciones policiales. Los casos en los cuales el imputado ha sido detenido en flagrancia se basan en la evidencia recolectada por la policía en el momento del arresto, luego de una investigación deficiente o inexistente (Ciocchini, 2018). Estudios como los de Fondevila et al. (2016) demuestran que esto no fue un problema sólo de la PBA, sino que ocurrió en otras jurisdicciones de América Latina. Esto es consecuencia de la promoción de soluciones negociadas en las cuales se sacrifica el debate de la evidencia presentada y de la legalidad de las actuaciones policiales. Por otra parte, si bien el objetivo de los procedimientos para delitos flagrantes era liberar recursos para los casos más complejos, en la práctica ha ocurrido lo contrario; los recursos son concentrados en estos casos que permiten mejorar las estadísticas judiciales en detrimento de casos más complejos que no siempre acaban en condenas (Hazán E Iud, 2010). Los casos complejos no suelen llegar a juicio, son resueltos a través de la negociación con el fiscal o por prescripción de la causa, y cuando lo hacen, los acusados deben esperar años detenidos (Ciocchini, 2018).

\section{La pérdida de liderazgo de los jueces}

Las reformas procesales en la PBA se han desarrollado en una constante tensión entre las aspiraciones democráticas y la demanda punitiva fomentada por la sensación de inseguridad y la politización del delito (Gutiérrez, 2017). Esta tensión ha redefinido el rol de los jueces, quienes han pasado de dirigir las investigaciones penales, establecer qué actos se ajustan a la ley y qué castigo debe sufrir el condenado, a un rol de control técnico indirecto, el cual en muchos casos se limita a convalidar las decisiones tomadas por fiscales o la policía.

La mayoría de los entrevistados acuerdan que este traspaso de facultades del juez al fiscal era necesario. Por ejemplo, un juez justificaba la reforma aduciendo que "[v]a ser muy difícil que un juez decrete la nulidad de algo que el mismo hizo por más que sea nulo." (juez argentino 1, comunicación personal, 17 de diciembre de 2010). 
Sin embargo, la reforma no eliminó el problema de imparcialidad, sino que lo trasladó al fiscal, como señalaba otro de los entrevistados: "El juez instructor y todas las objeciones apuntando a su [falta de] imparcialidad, por ahí no se habían formulado antes porque pensaban que los jueces actuaban imparciales muchas veces. Con la objetividad que después se le impuso al fiscal (...) [es similar a la situación del] juez instrucción" (Subsecretario de la Sala de Relatoría Penal, comunicación personal, 29 de diciembre de 2010).

Este problema se agrava al promover el uso de la discrecionalidad fiscal, por ejemplo, para archivar causas u ofrecer acuerdos de juicio abreviado.

La pérdida de liderazgo debe ser entendida como resultado de factores institucionales y sociales. En primer lugar, los jueces y la institución judicial sufren de una seria falta de confianza por parte de la población (Oyanedel, 2016). Esta falta de confianza está fundada en un discurso que sostiene que, ante la sensación de inseguridad vivida por la población, los jueces protegen a los delincuentes en vez de castigarlos. Este discurso, repetido por medios de comunicación y políticos, ha calado hondo, e incluso se manifiesta entre los jueces penales como una confrontación ideológica entre jueces progresivos y conservadores.

Los jueces, fiscales y abogados defensores progresistas son usualmente etiquetados por medios de comunicación y políticos como "garantistas". El garantismo es una ideología jurídica desarrollada por el jurista italiano Luigi Ferrajoli (2001) cuyo principio fundante es la creencia que el derecho debe entenderse como un sistema de garantías, entendidas como técnicas normativas de tutela de los derechos subjetivos de los individuos, frente al poder, ya sea este público o privado (Carbonell, 2006, p. 4). El garantismo penal propone un derecho penal mínimo, es decir, un derecho penal que busca imponer límites al poder punitivo del estado (Carbonell, 2006, p. 6). Sin embargo, el término es usado en forma despectiva por políticos y periodistas para criticar a actores judiciales, pero en especial a jueces, por su supuesta interpretación del derecho en favor de los criminales.

Durante las entrevistas, si bien ningún juez abiertamente se presentó cómo "garantista" ni a favor de políticas de "mano dura", en sus declaraciones se observa claramente su posicionamiento. Por ejemplo, un juez 
sostuvo que "[...]garantista en un sentido [...] es raro como el termino terminó siendo algo peyorativo cuando en la realidad garantista es que en principio se respeten los derechos de cada uno, pero bueno se hace [ver] como algo negativo" (juez argentino 1, comunicación personal, 17 de diciembre de 2010). Otro juez explicaba que tenía "un convencimiento absoluto de que el punto de vista criminológico, de la sociología del control, lo único que podemos hacer es evitar todo lo posible aquello que su prisionización es dañosa (sic) y únicamente mandar gente presa cuando realmente no existe otra solución cultural a este problema. A mí no me van a venir con teorías [de] re[habilitación]. [...] [C]omparto los puntos de vista de Zaffaroni en muchas cosas [...] es hermoso discurso [...] pero por momentos es un García Márquez del derecho penal" (juez argentino 2, comunicación personal, 13 de diciembre de 2010).

Frente a esta perspectiva, otro grupo de jueces considera que la función del juez no es "crear" derecho, sino aplicarlo, es decir, reconocen la necesidad de interpretación jurídica, pero sostienen que la ley es mucho menos ambigua de lo que se sostiene y que el jurista debe evitar ocupar el rol del legislador. De esta forma, un juez entrevistado señalaba: "El código [penall sale [promulgado] y los que lo resuelven son los legisladores y el juez lo que tiene que hacer [...] es aplicarlo porque si no habría una intromisión en la competencia de otro órgano del estado" (juez argentino 3, comunicación personal, 10 de agosto de 2010). Estos jueces suelen buscar ofrecer una interpretación lo más literal posible de la ley. Así un juez señalaba que: "a veces no es necesario interpretar, la ley literalmente es clara y no es necesario interpretarla más allá de lo que dice [...]" (juez argentino 4, comunicación personal, 10 de agosto de 2010). O como sostenía en forma similar una jueza entrevistada: "Yo tengo como norma el apego a la letra [...] soy bastante estricta, siempre trato en la interpretación, en lo que te da a lugar a interpretación porque hay normas que no, pero en general apegarme mucho a la letra de la ley(...) mi manera de efectuar el análisis es estrictamente literal" (juez argentino 5, comunicación personal, 13 de agosto de 2010).

Sin embargo, en un contexto de politización del delito, con constantes cambios legislativos que buscan expandir el poder punitivo del estado, el resultado de dicha interpretación 'literal' suele resultar en la convalidación de políticas de "mano dura". Aún más, la supuesta interpretación 
literal de la ley que estos jueces sostienen en muchos casos desconoce la primacía de la norma constitucional, es decir, las leyes deben ser interpretadas, en especial desde la vigencia de las nuevas constituciones de finales del siglo XX, en relación con las garantías constitucionales que tienen prioridad sobre cualquier otra norma. Por lo tanto, el juez debe aplicar normas penales solo si no viola las garantías constitucionales. El problema es el alcance que se le da a esas garantías constitucionales. En definitiva, cómo reconocía un juez, la ley ofrece un amplio espacio para la interpretación y el sistema penal "puede ser una picadora de carne si los fiscales y jueces de garantía son una picadora de carne y puede ser un procedimiento respetuoso de todas las garantías constitucionales si los jueces y los fiscales son respetuosos de las garantías constitucionales." (juez argentino 6, comunicación personal, 16 de diciembre de 2010). Estas tensiones dentro de la institución judicial hacen evidente hacia afuera que los jueces tienen ideologías que afectan la forma en la que juzgan. En un clima de inseguridad y desconfianza hacia las instituciones públicas, estas tensiones refuerzan la desconfianza hacia los jueces, ya que no se reconoce en ellos el liderazgo moral e intelectual para definir lo que es delito y cómo debe ser castigado.

Esta pérdida de liderazgo no ocurre sólo por tensiones dentro de la institución judicial, sino también por una pérdida de liderazgo hacia la policía, la otra institución encargada de imponer el poder punitivo. En el viejo CPC de la PBA los jueces dirigían la investigación policial, mientras que en el nuevo CPC son los fiscales los encargados de ello. El papel de los jueces se ha reducido a controlar la legalidad de las actuaciones a través de otorgar o denegar las solicitudes de medidas de coerción (por ejemplo, la prisión preventiva) y probatorias (por ejemplo, el registro domiciliario). De esta forma, en la práctica el papel de los jueces se ha redefinido, de ser quienes activamente lideraban a la policía, a ser quienes ejercen un papel reactivo de control técnico de la legalidad de las actuaciones de los fiscales y la policía.

Por otra parte, las reformas procesales han contribuido a la pérdida de liderazgo de los jueces. Uno de los factores que producen desconfianza en la población es la demora judicial. Esta demora ha sido denunciada por medios de comunicación y políticos, y se ha sostenido que acaba resultando en impunidad para los delincuentes. Las sucesivas reformas 
han buscado justificar en esta demora judicial la progresiva imposición de una lógica gerencialista que discipline la labor diaria de los jueces (Ciocchini, 2014, 2018). Aunque las reformas de tinte gerencial no llegaron a imponer la medición del desempeño de los jueces en términos de cantidades de sentencias condenatorias, sí han promovido un giro desde la preocupación por el caso individual hacia la cartera de casos. Este giro significa que, mientras en el pasado la lógica judicial priorizaba alcanzar la comprensión más acabada de los hechos del caso y de la ley aplicable por sobre el tiempo requerido para hacerlo, en la lógica gerencial se prioriza la resolución de la mayor cantidad de casos por sobre la discusión en profundidad del caso individual. Esto no es problemático en sí, pero sí en un contexto en el cual los casos requieren una discusión profunda porque están basados en la actuación de la policía, una institución que, en la mayoría de los países del Sur Global, se encuentra altamente cuestionada. De esta forma, la lógica gerencial promueve mecanismos para alcanzar el resultado deseado, es decir, la resolución de la mayor cantidad de casos, a través de mecanismos más económicos que el juicio, tales como la negociación de culpabilidad, que no permiten un análisis profundo de la evidencia ofrecida por el fiscal y la policía. De esta forma, la lógica gerencial lentamente disuelve la base de las reformas, el adversarialismo (el enfrentamiento entre el fiscal y el acusado ante un tercero imparcial, el juez) y lo reemplaza por un tipo de administrativización de la justicia que se centra en la maximización de la eficiencia del sistema, a través de ofrecer soluciones estandarizadas para la resolución de casos. Por otra parte, la actuación de los fiscales, cuya actuación está en cierta medida dirigida por las directivas promulgadas por sus superiores, se ha focalizado en delitos simples, particularmente en aquellos en los que los imputados hayan sido detenidos mientras los cometían forzando a los jueces a centrar su atención en estos casos.

Por último, los jueces operan bajo la amenaza de ser objeto de la crítica de los medios de comunicación o los sectores políticos, en caso de tomar decisiones que favorezcan a los acusados (Ciocchini, 2014; Kostenwein, 2015; Flom \& Post, 2016). Como señala acertadamente Kostenwein (2015), el discurso de la prensa sobre el sistema de justicia penal no es homogéneo. Sin embargo, como él mismo sostiene, la prensa tiende a legitimar la asociación entre castigos más severos y prevención del delito. Por otra 
parte, Flom y Post (2016) explican que el gobierno y los políticos, en el actual contexto de debilidad institucional y sensación de inseguridad, buscan evitar ser responsabilizados de no evitar el aumento del delito por la población. De esta forma, tienden a apoyar políticas punitivas de "mano dura". A su vez, los políticos culpan públicamente a los jueces de no castigar a los delincuentes. Los jueces deben operar condicionados por esta falta de respaldo institucional, sabiendo que si el acusado que absuelven o liberan en una causa vuelve a estar involucrado en un hecho delictual en el futuro, se los culpará por ello.

En conclusión, los jueces penales en la PBA perdieron su liderazgo en un contexto de sensación de inseguridad y politización del delito. Esta pérdida fue posible gracias a las reformas judiciales que cambiaron las relaciones de poder dentro de la administración de justicia penal en favor de los fiscales. Estas reformas promovieron la paulatina introducción de una lógica gerencial que ha afectado la racionalidad que guía la actividad judicial. Esta lógica gerencial también ha contribuido a la pérdida de liderazgo de los jueces, ya que, al favorecer mecanismos alternativos por sobre el juicio, desdibuja la función del juez que pasa a ser un mero contralor indirecto de la actividad de los fiscales. El espacio perdido por los jueces es ocupado en parte por los fiscales. Sin embargo, los fiscales no tienen el mismo poder que tenían los jueces bajo el sistema inquisitivo (notablemente no tienen poder jurisdiccional). Esta debilidad de los fiscales le permite al gobierno, es decir, al poder ejecutivo, en parte a través de la policía, ejercer el liderazgo en la política criminal.

\section{Filipinas: cuando los jueces son ignorados}

En Filipinas se observa un caso más extremo de pérdida de liderazgo por parte de los jueces. Frente a la crisis del sistema judicial se han implementado reformas que buscan simplificar los procedimientos y favorecer soluciones pactadas que eviten el juicio oral. El impacto de estas reformas en su rol se ha agravado por la presión política impuesta por Duterte y su "guerra contra las drogas". Los jueces se han retirado por completo del debate y la implementación de las políticas contra el crimen. Como resultado, por una parte, la violencia estatal se ha desatado sin ningún 
control legal resultando en miles de ejecuciones por la policía, y por la otra, los tribunales, enfrentando con recursos escasos la masiva entrada de casos de drogas, han limitado su contralor sobre el accionar policial al evitar llevar las causas a juicio recurriendo a mecanismos de negociación de culpabilidad (plea bargaining).

\section{La neutralización del poder judicial}

En Filipinas, la ineficiencia burocrática del poder judicial, evidenciada por el brutal retraso acumulado en las causas judiciales, ha afectado el liderazgo de los jueces. Los juzgados filipinos llevan sufriendo demora por décadas, impidiéndoles cumplir su función adecuadamente (Tadiar, 1980). Estas demoras han sido reconocidas públicamente por las autoridades del poder judicial (Torres-Tupas, 2014). Phelim Kine, subdirector de la División de Asia de Human Rights Watch, ha declarado que "la realidad es que el sistema judicial no funciona en Filipinas" (Taub, 2016).

El severo nivel de demora judicial ha abierto el camino a una serie de reformas patrocinadas por donantes internacionales del Norte Global en las últimas décadas. Según la Suprema Corte de Filipinas, al menos 40 estudios técnicos sobre la administración judicial se han completado desde la década del noventa para apoyar programas de reformas, tales como el de Asistencia técnica del Poder Judicial de Filipinas sobre Justicia y Desarrollo (1996-1999), el Plan de Acción para el Poder Judicial (1999), el Programa de Acción para la Reforma Judicial (2001-2010), el Proyecto de Apoyo a la Reforma Judicial (2001-2012), y el Plan de Desarrollo de la Judicatura y la Profesión Jurídica (JLPDP). La reforma más reciente en los juzgados filipinos se ha centrado en mejorar su eficiencia en la resolución de causas a través de la implementación de juicios continuos. Este programa, que ha sido promovido por la American Bar Association, proporciona pautas para llevar a cabo juicios y regula las mociones que las partes pueden plantear, acortando los plazos para presentarlas y prohibiendo las que considera no esenciales. El programa también regula las agendas de los juzgados al exigir que los juicios se realicen de lunes a jueves, dejando los viernes libres para resolver mociones, acusaciones y audiencias previas al juicio (Punay, 2017). Si bien los actores judiciales entrevistados fueron favorables a este nuevo esquema de juicios 
continuos, muchos plantearon la insuficiencia de recursos humanos para poder cumplir con los plazos que fija el programa, como por ejemplo una fiscal que sostuvo que "[...] los juzgados reciben tantos casos de drogas, los fiscales estamos verdaderamente cansados y para colmo hay un esquema de juicios continuos aquí [...] un fiscal, imi Dios!, tiene que escuchar alrededor de 20 casos en juicio (por día) [...." (fiscal filipino 1, comunicación personal, 21 de mayo de 2018).2

Más allá de la mirada favorable de los actores judiciales al programa de juicios continuos, sus límites se evidencian en la situación de los acusados por delitos de drogas. Según la Agencia de Administración de Cárceles y Penología de Filipinas (BJMP por sus siglas en inglés) en mayo de 2018, más de un año después de la implementación de los juicios continuos, solo 648 de los 102.692 individuos en prisión por delitos de drogas han sido juzgado, el resto se encontraba detenido esperando su juicio (BJMP, 2018). Esto evidencia los límites del sistema judicial para procesar el volumen de casos existente.

Frente a la incapacidad de los juzgados filipinos para responder a las expectativas de la población, Duterte ha ofrecido como alternativas políticas de mano dura, llegando incluso a apoyar abiertamente la política de disparar a los sospechosos (Holmes, 2016). El discurso de Duterte debe comprenderse en el marco de un país en el cual, a pesar del crecimiento económico constante durante la última década, la pobreza y la desigualdad se han mantenido alarmantemente altas. Frente a la decepción de los ciudadanos con la élite gobernante, Duterte ofrece una alternativa populista (Timberman, 2016). Los escándalos en los cuales el poder judicial estuvo involucrado en la última década evidenciaron frente a la población su conexión con la misma elite política que los ha decepcionado (Ciencia, 2012). Duterte ha alimentado esta narrativa al acusar públicamente a los jueces de corrupción y colusión con narcotraficantes (Corrales, 2016). Es sintomática la reacción de la presidente de la Suprema Corte en aquel momento, María Lourdes Sereno, ante las acusaciones de Duterte. En una carta abierta al presidente Sereno le advirtió a Duterte que era función de la Suprema Corte castigar a los jueces que cometieran un delito y le solicitaba que, en aras de preservar la confianza 
en el poder judicial, evitará realizar acusaciones públicas de ese tipo. La respuesta de Duterte fue amenazarla públicamente, ordenándole no "(...) crear una crisis porque de lo contrario, ordenaré que nadie en el poder ejecutivo te respete" (Ramos, 2017). Este duro tratamiento evidenció la debilidad del poder judicial y la falta de apoyo del gobierno. Un año después, Sereno fue destituida en un proceso muy politizado, acusada de no haber declarado la totalidad de sus bienes personales.

Con el poder judicial neutralizado, Duterte ha abordado su guerra contra las drogas replicando las tácticas que utilizó en Davao City cuando era alcalde: desatar la violencia policial no solo contra los traficantes de drogas, sino también contra los consumidores (Rauhala, 2016). Ha utilizado el lenguaje de la guerra contra las drogas y la criminalidad para explotar los temores y las ansiedades de la población. Pero el apoyo de la población no se basa meramente en el miedo, sino, como sostiene Curato (2016), en la esperanza de que una desviación radical de la política del elitismo, tal como la que ofrece Duterte, mejore sus condiciones de vida. Curato (2016) ofrece un esclarecedor análisis al respecto: “El predecesor de Duterte, Benigno S. Aquino, priorizó programas que luchan contra los crímenes de una manera deliberada, programática y sostenida... [mientras que Duterte ha prometido] superar la burocracia corrupta en el sistema de justicia y alcanzar la paz y el orden de manera decisiva y rápida" (p. 96, traducción del autor). De esta forma, Duterte ha logrado asociar a los jueces con la burocracia elitista e ineficiente que gobernó Filipinas y de esta forma neutralizar toda posibilidad de crítica a sus políticas criminales.

\section{El rol de los jueces en la "guerra contra las drogas"}

Duterte al relegar a los jueces, ha permitido que la policía actúe sin la contención que la ley en el estado de derecho ofrece. Esto es preocupante porque la policía en Filipinas, en forma similar a la de la PBA, ha sido denunciada en múltiples casos por corrupción y abuso policial. Por lo tanto, el contralor de su actividad, a través de la evaluación de la evidencia presentada en los casos penales, era una función esencial de los jueces (Hapal \& Jensen, 2017). Sin el contralor judicial y con el apoyo del poder ejecutivo, las fuerzas policiales han operado sin la responsabilidad 
y la transparencia requeridas por el estado de derecho, priorizando así el control del delito por sobre el debido proceso, lo que ha producido como resultado la muerte de casi 20.000 personas en la "guerra contra las drogas" (Gavilan, 2018).

Pero, la "guerra contra las drogas" de Duterte se caracteriza no solo por las ejecuciones extrajudiciales, sino también por las detenciones masivas. Mientras que el número de arrestos por delitos de drogas se mantuvo estable entre 2005 y 2015, variando desde un mínimo de 6.259 en 2010 a un máximo de 19.432 en 2015 (Philippine Statistics Authority, 2017), en el 2016 se detuvieron a 28.056 y a 75.008 en el 2017 (Leonen, 2018). Más aún, según el BJMP en mayo de 2018 , un 70,88\% de la población carcelaria se encontraba detenida por delitos de droga (BJMP, 2018). De esta forma, los jueces se vieron inundados de nuevos casos en el contexto de ineficacia crónica que fue descripto previamente. Como sostuvo un juez entrevistado: "un juzgado puede tener más de 1000 casos. [...] En razón del número de nuevos casos de drogas asignados, incluyendo casos de usuarios y poseedores de drogas, es mayor el número de casos nuevos al de concluidos" (juez filipino 1, comunicación personal, 5 de junio de 2018).

Esto ha impactado en la capacidad de los jueces para controlar la legalidad de la actuación policial. Es importante entender la importancia de la función de control que ejercían jueces y fiscales. En 2014, del 20 al 30 por ciento de los casos por delitos de drogas fueron desestimados por los fiscales o jueces debido a falencias en el procedimiento (De Jesus, 2014). Dos años después, una jueza que se presentaba como candidata para la Suprema Corte, declaraba en una audiencia pública que "había absuelto a los acusados en 7 de cada 10 casos por delitos relacionas con drogas" porque "las ordenes de registro no se implementaban correctamente, la cadena de custodia había sido rota, o el caso era muy dudoso" (Francisco, 2016, [en línea]) Esta descripción fue corroborada en las entrevistas con los actores judiciales; así un fiscal explicaba que: "[...] el problema es realmente con el cumplimiento (de la ley) y la actuación de los oficiales de policía porque eso afecta el procesamiento del caso [...]. Si los policías no cumplieron con los requisitos de la ley, el abogado defensor se hará una panzada en el interrogatorio. Tristemente, el mayor problema se encuentra en la custodia de la evidencia y la forma del arresto [...] 
(fiscal filipino 2, comunicación personal,23 demayo de 2018). En forma similar un juez sostenía que: "hay muchos casos de drogas en los que hay tantas detenciones y la investigación (es tan compleja), que la policía a veces se olvida, o intencionalmente se olvida, las circunstancias de la investigación y de la detención. Por lo tanto, si hay un lapsus o un error en el testimonio de la policía, o una inconsistencia entre su testimonio escrito y el testimonio oral durante la audiencia de juicio, el acusado será absuelto" (juez filipino 2, comunicación personal, 5 de junio de 2018). Por su parte otro fiscal, reconocía esta situación, pero consideraba que el problema no era el accionar policial sino los requisitos de la ley: "la normativa es muy estricta, y los procedimientos no son seguidos por los oficiales de policía, aunque debemos admitir que no es su culpa porque las leyes son demasiado estrictas y difíciles de cumplir" (fiscal filipino 3, comunicación personal, 23 de mayo de 2018).

Junto con la entrada masiva de casos de drogas, la función de contralor de jueces y fiscales se vio afectada por el temor a ser acusados públicamente por el gobierno si desestiman casos en los cuales la evidencia ofrecía dudas. Un fiscal explicaba su reticencia a archivar casos: "Si (el fiscal) desestima un caso se abre un expediente administrativo, cuestionándolo: ¿Por qué desestimó (el caso)? ¿Usted sabe que el primer objetivo del gobierno es erradicar los casos de drogas y los delitos de drogas? [...] Y si eres muy técnico al respecto, y descartas el caso, entonces las autoridades sospechan: "Puede que estés pagado por narcotraficantes" [...] Entonces, ¿Qué hacemos? Trasladamos el problema a los jueces (para que ellos decidan)." (fiscal filipino 4 entrevistado, comunicación personal, 22 de mayo de 2018).

La situación para jueces, fiscales y abogados defensores era aún más difícil por la prohibición en la legislación penal de los mecanismos de negociación de culpabilidad (plea bargaining) en los casos de drogas. De esta forma, debían enfrentar la entrada masiva de casos, sin poder desestimar ninguno de ellos sin correr el peligro de ser acusados públicamente y forzados a llevarlos a juicio. Esta situación se volvió inmanejable tanto para los juzgados como para los fiscales y los abogados defensores públicos, lo que nos llevó a cuestionar la prohibición de usar mecanismos de negociación.

En junio de 2016, a solo seis meses del inicio de la "guerra contra las drogas", en un caso en el que el acusado, Salvador Estipona Jr., fue acusado de posesión de drogas peligrosas (Sección 11, Artículo II, RA No. 9165), 
el defensor público presentó una moción para celebrar un acuerdo de negociación de culpabilidad. El acusado ofrecía declararse culpable de un delito menor, la posesión de parafernalia de drogas (Sección 12, Artículo II, AR No. 9165) y solicitaba una pena de rehabilitación ya que no tenía antecedentes y la cantidad de drogas en su poder era mínima (Estipona, V. Juez Lobrigo, GR No. 226679). La fiscalía se opuso a la moción y el juez la rechazó en julio de 2016. Sin embargo, tanto la fiscalía como el juez reconocieron que había mérito en la solicitud, especialmente considerando que la intención de la ley era rehabilitar a los acusados de delitos relacionados con las drogas. Sin embargo, sostuvieron su rechazo en la prohibición prescrita por la ley y las posibles consecuencias de declarar su inconstitucionalidad. Ante el rechazo del juez, Estipona presentó en septiembre de 2016 una apelación ante la Corte Suprema de Filipinas cuestionando la constitucionalidad de la Sección 23 de R.A. No. 9165 que prohíbe la negociación de culpabilidad en casos de drogas. La apelación argumentaba que la negociación de culpabilidad era un derecho constitucional del acusado y que su denegación no sólo era arbitraria, sino que violaba el debido proceso y la igualdad ante la ley. La Corte Suprema de Filipinas resolvió a favor de la petición en agosto de 2017 (Estipona, V. Juez Lobrigo, G.R. No. 226679), declarando inconstitucional la prohibición de negociación de culpabilidad (Sección 23 de R.A No. 9165). Cuando la decisión se convirtió en definitiva y ejecutoria en noviembre de 2017 la Asociación de Jueces de Filipinas presentó ante la Corte Suprema una propuesta de "Marco de negociación de culpabilidad sugerido en casos de drogas" que definía frente a cada delito los límites aceptables para la negociación de culpabilidad. Con modificaciones menores, este marco fue adoptado por la Corte en abril de 2018.

Si bien no hay todavía estadísticas publicadas que den cuenta del impacto de permitir la negociación de culpabilidad en casos de drogas, en un artículo de un diario filipino se sostenía que, en julio de 2018, a sólo meses de haber sido permitida, 500 detenidos habían sido liberados en la región de Tagaytay gracias a este mecanismo (Punay, 2018). Esto fue confirmado en las entrevistas realizadas. Un efecto colateral de la decisión de permitir la negociación de culpabilidad en casos de drogas ha sido el cambio drástico en la severidad del castigo para consumidores de drogas. Gracias a la negociación de culpabilidad, los consumidores que previamente 
enfrentaban penas de entre 12 a 20 años de prisión, ahora pueden recibir menos de 2 años de prisión, e incluso ser favorecidos con la suspensión de la pena a prueba (probation). Este cambio es significativo dado que la retórica de la "guerra contra las drogas" no ha cambiado y puede ser leído como un primer paso en la recuperación del liderazgo ético por parte del Poder Judicial. No obstante, también debe tenerse en cuenta que, si bien el gobierno, a través de la Oficina del Procurador General, se opuso en el caso Estipona a declarar inconstitucional la prohibición de la negociación de culpabilidad en casos relacionados con drogas, los fiscales, dependientes del Departamento de Justicia, y la policía, principal reclamante en casos relacionados con drogas, fue generalmente favorable a la negociación de culpabilidad, como lo demuestran las entrevistas presentadas anteriormente. De esta forma, también puede leerse la decisión como una forma del gobierno de adaptar su estrategia penal sin pagar el precio político de reconocer el exceso de política criminal.

En todo caso, si bien la negociación de culpabilidad en casos de drogas permitió a los jueces y a los fiscales resolver el problema que les significaba la carga masiva de casos de drogas, evitar la exposición política que implicaba desestimar o absolver los casos en los que la evidencia fuera débil y al mismo tiempo reducir significativamente el desproporcionado castigo impuesto a los consumidores de drogas, esta también ha neutralizado el control que ejercían sobre la policía al evitar la realización de la audiencia de debate, la fase en la cuál a través del examen de la evidencia se ponía en cuestión la legalidad de la actuación policial. Los casos que previamente eran absueltos ahora reciben una pena, si bien mínima en comparación a las penas que podría recibir en un juicio, y la actuación policial es legitimada por los jueces. Dada las numerosas denuncias en contra de la policía, la propia admisión de los entrevistados y las deficiencias en el accionar policial, esto es seriamente preocupante y genera dudas sobre el rol que cumplen los jueces filipinos en el marco de la "guerra contra las drogas".

\section{Conclusiones}

El análisis comparativo del rol de los jueces en la prevención y castigo del delito en el Sur Global es importante para comprender las particularidades de las sociedades periféricas y semi-periféricas e identificar factores 
sociales y políticos comunes que pueden dar lugar al surgimiento de tendencias punitivas peligrosas.

En las sociedades del Sur Global, la actuación de los jueces está constreñida por varios factores. Por una parte, deben operar en un contexto de sensación de inseguridad, basado en un aumento real de los hechos delictivos, pero a su vez, notablemente amplificado por los discursos de los políticos y los medios de comunicación. Por otra parte, estos discursos tienden a responsabilizar a los jueces de impedir con sus tecnicismos e ideologías progresistas el actuar a la policía. Esta desconfianza de la población frente a la actuación de los jueces es alimentada por la inoperancia que ofrece una institución que sufre una demora crónica. La incapacidad de los tribunales le ha abierto el camino a una serie de reformas procesales que han buscado aumentar su eficiencia; sin embargo, lo han hecho a costa de reducir la capacidad de los jueces para ejercer el necesario control de la actividad policial. Al mismo tiempo, el gobierno, a través de la policía, ha tomado el liderazgo en la prevención y castigo del delito, con estrategias que suelen violentar las garantías que ofrece el estado de derecho.

Un proceso similar de pérdida de liderazgo de los jueces con el surgimiento de un punitivismo penal ha tenido lugar en el Norte Global. Sin embargo, el nivel y tipo de criminalidad y la incapacidad de las burocracias judiciales para lidiar con el delito en el Sur Global allana el camino para un tipo de punitivismo popular más peligroso. En sociedades con un legado autoritario, el control de la policía y la protección del debido proceso debe ser prioritario. El caso de Filipinas muestra la violencia extrema que puede resultar de relegar a los jueces en favor de la policía en la prevención y el castigo del delito. Es una señal de advertencia para otras sociedades en el Sur Global que sufren de un contexto similar; un ejemplo de este peligro son las recientes declaraciones del presidente de Indonesia, Joko Widodo, quien, siguiendo las políticas de Duterte, en un esfuerzo para erradicar el consumo de drogas en el país, ordenó a la policía disparar contra narcotraficantes que se resistieran al arresto (Agence France-Presse, 2017). Esto demuestra la necesidad de construir un poder judicial fuerte, que pueda tomar el liderazgo político y moral para enfrentar las estrategias punitivas populares. 
Por otro lado, el caso de Argentina demuestra que las reformas gerenciales también pueden debilitar el liderazgo de los tribunales, reduciendo su capacidad para controlar a la policía. La introducción de mecanismos alternativos de resolución de casos que buscan mejorar la eficiencia de los tribunales a través de evitar el juicio, tales como la negociación de la declaración de culpabilidad, son problemáticos en sociedades con policías corruptas y autoritarias.

El análisis comparativo entre las sociedades del Sur Global permite identificar problemas comunes que surgen de condiciones económicas y políticas similares. Todavía hoy en día, los diagnósticos y soluciones a problemas de gobernanza y de criminalidad se siguen importando de las sociedades del Norte Global. Reconociendo el fracaso de estas reformas, es hora abrir un dialogo Sur-Sur para compartir nuestras experiencias y aprender de ellas.

\section{Referencias}

Agence France-Presse. (2017). Shoot Drug Traffickers if They Resist Arrest-Indonesia's Widodo, Inquirer.net. Recuperado de http://newsinfo.inquirer.net/916347/ shoot-drug-traffickers-if-they-resist-arrest-indonesias-widodo\#ixzz4sKtMdHW4 (Último acceso el 23 de julio de 2017).

Bergman, M. (2006). Crime and Citizen Security in Latin America. Latin American Research Review, 41(2), 213-227.

Bergman, M. \& Langer, M. (2015). El nuevo código procesal penal nacional acusatorio: aportes empíricos para la discusión en base a la experiencia en la Provincia de Buenos Aires. Revista de derecho procesal penal, 1, 51-80.

Binder, A. (2002). Los oficios del jurista: La fragmentación de la profesión jurídica y la uniformidad de la carrera judicial, Sistemas judiciales, 1, 34-53. BJMP. (2018). PDL with Drug Cases (As of May 2018). Recuperado de https:// www.bjmp.gov.ph/datstat.html

Carbonell, M. (2006). Presentación: La teoría garantista de Luigi Ferrajoli. En Luigi Ferrajoli, Garantismo penal (pp 3-9). México D.F.: UNAM.

Carranza, E. (1996). Estado actual de la prisión preventiva en América Latina y comparación con los países de Europa. Jueces para la Democracia, 26, 81-88.

CEJA. (2005a). Reformas procesales penales en América Latina: Resultados del proyecto de seguimiento (Volumen 1). Santiago de Chile: CEJA. 
CEJA. (2005b). Reformas procesales penales en América Latina: Discusiones locales (Volumen 2). Santiago de Chile: CEJA.

CEJA. (2008). Reformas Procesales Penales en América Latina: Resultados del Proyecto de Seguimiento (Volumen 4). Santiago de Chile: CEJA.

Chua, M. (2012). TORTYUR: Human Rights Violations During the Marcos Regime, Recuperado de https://www.academia.edu/7968581/TORTYUR_Human_ Rights_Violations_During_The_Marcos_Regime

Ciencia Jr., A. (2012). From Judicialization to Politicization of the Judiciary: The Philippine Case. En B. Dressel, (Ed.), The Judicialization of Politics in Asia (pp. 117-138). Abingdon, Inglaterra: Routledge.

Ciocchini, P. (2013a). La persistencia del expediente judicial: el caso de la administración de justicia penal bonaerense, Derecho y Ciencias Sociales, 8, 151-164. Ciocchini, P. (2013b). Moldeando el problema y sus soluciones: los discursos técnicos sobre la demora en la administración de justicia penal, Crítica Jurídica, 36, 95-123.

Ciocchini, P. (2014). Campaigning to Eradicate Court Delay: Power Shifts and New Governance in Criminal Justice. Crime, Law and Social Change, 61, 61-79. Ciocchini, P. (2018). Reformers' Unfulfilled Promises: Accountability Deficits in Argentinean Criminal Courts. International Journal of Law in Context, 14(1), 22-42. Ciocchini, P. E Kostenwein, E. (2017). Presentación del dossier Estudios actuales sobre la justicia penal. Derecho y Ciencias Sociales, 17, 1-6.

CONADEP. (2010). Nunca más: Informe de la Comisión Nacional sobre la Desaparición de Personas, CABA: Eudeba.

Corrales, N. (2016). Duterte's New Drug List: 40 Judges, '1 page' for Chinese Suspects. Inquirer.net, Recuperado de http://newsinfo.inquirer.net/817675/ dutertes-new-drug-list-40-judges-1-page-forchinese-suspects\#ixzz4sJjzalDo (Último acceso 7 de mayo de 2018).

Curato, N. (2016). Politics of Anxiety, Politics of Hope: Penal Populism and Duterte's Rise to Power. Journal of Current Southeast Asian Affairs, 35, 91-109. De Jesus, J. (2014). High Conviction Rate of Drug Cases Seen with New Law. Inquirer.net. Recuperado de https://newsinfo.inquirer.net/626229/highconviction-rate-of-drugs-cases-seen-with-new-law (Último acceso el 19 de octubre de 2018).

Duce, M. (ed.) (2005). Reformas Procesales Penales en América Latina: Experiencias de innovación (Volumen 3). Santiago de Chile: CEJA.

Duce, M. (2009). Reforma de la justicia penal en América Latina: Una perspectiva panorámica y comparada, examinando su desarrollo, contenidos y desafíos. UDP Public Policy Series-Working Papers, 3, 1-39. 
Duce, M., Mera, A. E Riego, C. (2002). La capacitación interinstitucional en la reforma a la justicia criminal en Chile. Sistemas Judiciales, 1, 55-72.

Ferrajoli, L. (2001). Derecho y razón, Madrid: Trotta.

Flom, H. \& Post, A. (2016). Blame Avoidance and Policy Stability in Developing Democracies, The Politics of Public Security in Buenos Aires. Comparative Politics, 49(1), 23-42.

Fondevila, G., Langer, M., Bergman, M., Vialta, C. E Mejía, A. (2016). ¿Cómo se Juzga en el Estado de México? Una Radiografía de la Operación del Sistema de Justicia Penal Acusatorio, Ciudad de México: CIDE. Recuperado de http:// mexicoevalua.org/wp-content/uploads/2016/10/Como_Juzga_Edomex.pdf

Francisco, K. (2016). “Davao Judge Explains to JBC High Rate of Acquittal in Drug Cases". Rappler. Recuperado de https://www.rappler.com/nation/152546-jbc-supreme-court-interview-adlawan-illegal-drugs

Fundamentos Ley 11.922 (n.d.) Recuperado de http://www.gob.gba.gov.ar/ legislacion/legislacion/f-11922.html

Ganon, G. (2008). ¿La "macdonalización" del sistema de justicia criminal?: La aceptación improvisada de los paquetes de reforma judicial para el tercer milenio. En R. Bergalli, I. Rivera Beiras, \& G Bombini, G. (Eds.), Violencia y Sistema Penal (pp. 237-265). Buenos Aires, Argentina: Del Puerto.

Gavilan, J. (2018). Justice Remains Elusive 2 Years into Duterte's Drug War. Rappler. Recuperado de https://www.rappler.com/newsbreak/in-depth/205921justice-elusive-war-on-drugs-duterte-second-year (Último acceso el 19 de octubre de 2018).

Gutiérrez, M. (2014). Acusatorio y Punitivismo: la triste historia de nuestras victorias garantistas, Revista Derecho Penal y Criminología, 8, 70-86.

Gutiérrez, M. (2017). Coyuntura y frentes de tormenta. La política criminal de la Provincia de Buenos Aires 1996-2014. En E. Kostenwein (ed.), Sociología de la Justicia Penal (pp. 261-303), Buenos Aires, Argentina: Ediar.

Hapal, K. E Jensen, S. (2017). The Morality of Corruption: A View from the Police in Philippines. En S. Jensen E M.K. Andersen (Eds.), Corruption and Torture: Violent Exchange and the Policing of the Urban Poor, Aalborg, Dinamarca: Aalborg University Press.

Hazán, L. E Riego, C. (2007). La oralidad en las etapas previas al juicio: La experiencia de Mar del Plata. En C. Riego (Ed.). Reformas procesales en América Latina: Resultados del proyecto de seguimiento (Volumen 4) (pp. 255-294). Santiago de Chile, Chile: CEJA.

Hazán, L. E lud, A. (2010). Informe de evaluación del proceso de fortalecimiento del sistema acusatorio en la Provincia de Buenos Aires - plan de flagran- 
cia. En Primer encuentro nacional Redex Argentina (pp. 161-235). Córdoba, Argentina: Advocatus.

Holmes, O. (2016, 14 de diciembre). Philippines President Rodrigo Duterte Says He Personally Killed Criminals, The Guardian, 14 de diciembre. Recuperado de https://www.theguardian.com/world/2016/dec/14/philippines-presidentrodrigo-duterte-personally-killed-criminals (Último acceso 7 de mayo de 2018). HRW. (2011). No Justice Just Adds to the Pain" Killings, Disappearances, and Impunity in the Philippines. Human Rights Watch. Recuperado de https://www.hrw. org/report/2011/07/18/no-justice-just-adds-pain/killings-disappearancesand-impunity-philippines

Kostenwein, E. (2016). La cuestión cautelar: El uso de la prisión preventiva en la provincia de Buenos Aires a partir de la ley 11.922, 1998-2013. Buenos Aires: Ediar.

Kostenwein, E. (2015). Prisión preventiva: Entre los medios de comunicación y las autoridades políticas, Revista Direito e Práxis, 6, 54-79.

Langer, M. (2007). Revolution in Latin American Criminal Procedure: Diffusion of Legal Ideas from the Periphery. American Journal of Comparative Law, 55, 617-676. Leonen, J. (2018). PDEA: 75,000 drug suspects arrested in 2017. Inquirer.net. Recuperado de https://newsinfo.inquirer.net/960768/pdea-75000-drugsuspects-arrested-in-2017

Ministerio de Seguridad de la Nación. (2017). Sistema Nacional de Información Criminal (SNIC): Año 2016 - Informe. Recuperado de https://estadisticascriminales.minseg.gob.ar/reports/Informe\%20SNIC\%202016.pdf

Oyanedel, J. (2016). Confianza en la justicia y la policía en América Latina: Análisis de los efectos de las reformas procesales penales (1995-2013). Reforma y Democracia, 141-164.

Palmieri, G., Martínez, M. J., Litvachky, P., Aliverti, A. E Hazán, L. (2004). Informe sobre el sistema de justicia penal en la Provincia de Buenos Aires. Buenos Aires: CELS.

Pasará, L. (2015). Reforma Procesal y Reforma Judicial. Recuperado de http://perso. unifr.ch/derechopenal/assets/files/temas/t_20080528_08.pdf

Philippine Statistics Authority. (2017). 2017 Philippine Statistical Yearbook. Quezon, Filipinas: PSA.

Punay, E. (2017). Speedy Justice Set to Roll Out Nationwide. The Philippine Star. Recuperado de https://www.philstar.com/headlines/2017/05/08/1691903/ speedy-justice-set-roll-out-nationwide

Punay, E. (2018). Plea Bargain Eases Drug Case Backlog. Philstar Global. Recuperado de https://www.philstar.com/headlines/2018/07/09/1831871/pleabargain-eases-drug-case-backlog 
Ramos, M. (2017). Days of Disquiet in Judiciary under Duterte. Inquirer.net. Recuperado de http://newsinfo.inquirer.net/916532/days-of-disquiet-in-judiciary-under-duterte

Ragragio, J. (2003). The Case of Metro Manila, Philippines. En Understanding Slums, Case studies for the Global Report on Human Settlements. Recuperado de http://www.ucl.ac.uk/dpu-projects/Global_Report/pdfs/Manila.pdf

Rauhala, E. (2016). Before Duterte Was the Philippines' President, He Was 'the Death Squad Mayor', The Washington Post. Recuperado de https://www. washingtonpost.com/world/asia_pacific/before-duterte-was-the-philippinespresident-he-wasthe-death-squad-mayor/2016/09/28/f1 d 1 ccc4-800b-11 e6ad0e-ab0d12c779b1_story.html

REDEX. (2010). Presentación red de capacitadores en reforma judicial Redex Argentina. En Primer Encuentro Nacional Redex Argentina (pp. 11-14), Córdoba: Advocatus.

Riego, C. (Ed.) (2007). Reformas Procesales Penales en América Latina: Resultados del Proyecto de Seguimiento (Volumen 4). Santiago de Chile: CEJA.

Suárez, A. L. E Palma Arce, C. (2010). Condiciones de vida en el conurbano bonaerense. En A. Rofma (Ed.), Sociedad y territorio en el conurbano bonaerense: un estudio de las condiciones socioeconómicas y sociopolíticas de cuatro partidos: San Miguel, José C. Paz, Moreno y Morón (pp. 25-102), Los Polvorines, Argentina: Universidad Nacional de General Sarmiento.

Tadiar, A. (1980). Some Role/Functions in the Administration of Criminal Justice. Philippine Law Journal, 55, 32-50.

Taub, A. (2016, 11 de septiembre). How Countries Like Philippines Fall into Vigilante Violence, The New York Times. 11 de septiembre. Recuperado de https://nyti.ms/2cF7kN6

Timberman, D. (2016). Elite Democracy Disrupted? Journal of Democracy, 27, 135-44.

Torres-Tupas, T. (2014). Sereno Seeks for More Budget for Judiciary Reforms, Inquirer.net. Recuperado de http://newsinfo.inquirer.net/640461/sereno-seeks-more-budget-for-judiciary-reforms

Ugolini, A. (2017). Legítimos policías: Etnografia de lo ilegal entre policías de la Provincia de Buenos Aires. CABA: Antropofagia.

Vogler, R. (2005). A World View of Criminal Justice. Aldershot, Inglaterra: Ashgate. 